\title{
A vantagem do incumbente nas eleições municipais e estaduais brasileiras: um estudo de 2000 a 2018
}

\author{
Ari Francisco de Araujo Júnior \\ Ibmec Minas Gerais, Belo horizonte, MG, Brasil \\ Tiago Silva Pires (Ibmec) \\ Ibmec Minas Gerais, Belo horizonte, MG, Brasil
}

\section{Resumo}

Este estudo busca averiguar a existência da vantagem do incumbente em eleições municipais e estaduais brasileiras. A metodologia adotada é a de pares repetidos de Brambor e Ceneviva (2011), na qual pares de candidatos que se enfrentam mais de uma vez são a unidade de análise. A grande vantagem de se utilizá-la reside na retirada de efeitos fixos de candidato e município. Encontramse evidências contrastantes em termos de vantagem do incumbente para eleições executivas de prefeitos e governadores. Estimou-se que prefeitos incumbentes sofrem uma desvantagem de 2,7 pontos percentuais nas eleições municipais brasileiras. Há evidências de queda na desvantagem do incumbente entre as eleições de 2000 e 2008. No entanto, observou-se um crescimento do fenômeno para os anos de 2012 e 2016. Por outro lado, governadores incumbentes gozam de uma expressiva vantagem de 9,5 pontos percentuais. A vantagem de governadores em exercício do cargo parece manter trajetória crescente de 1998 até 2010, quando atinge o máximo de 17,3 pontos percentuais.

Palavras-chave: vantagem do incumbente, eleições, Brasil 
La ventaja del incumbente en las elecciones municipales y estatales brasileñas: un estudio de 2000 a 2018

Este estudio busca descubrir sí existe ventaja del incumbente en las elecciones brasileñas tanto a nivel de los municipios como de los estados. La metodología utilizada es de los pares repetidos de Brambor y Ceneviva (2011), en el cual los pares de candidatos que se enfrentan más de una vez son la unidad de análisis. La gran ventaja de usarlo radica en la eliminación de los efectos fijos del candidato y del municipio. Se encuentra evidencia contrastante en términos de la ventaja del titular para las elecciones ejecutivas de prefectos y gobernadores. Se estimó que los prefectos incumbentes sufren una desventaja de 2,7 puntos porcentuales en las elecciones municipales brasileñas. Hay evidencia de caída en la desventaja del incumbente entre las elecciones de 2000 y 2008. Sin embargo, fue observado un crecimiento del fenómeno en los años de 2012 y 2016 . Por otro lado, gobernadores incumbentes gozan de una ventaja expresiva de 9,5 puntos porcentuales. La ventaja de los gobernadores en ejercicio del cargo parece estar en una trayectoria creciente de 1998 a 2010, en que alcanza el máximo de 17,3 puntos porcentuales.

Palabras clave: ventaja electoral, elecciones, Brasil

\section{Incumbency advantage in brazilian municipal and state elections: a study from 2000 to 2018}

The aim of this article is to investigate the occurrence of the incumbency advantage phenomenon in Brazilian local and state elections. The methodology adopted is that of repeated pairs of Brambor and Ceneviva (2011), in which pairs of candidates who face each other more than once are the unit of analysis. The greatest advantage of using it lies in the removal of candidate and municipality fixed effects. Contrasting evidence is found in terms of the incumbent's advantage for elections of mayors and governors. The results suggest that incumbent mayors suffer a disadvantage of 2.7 percentage points in the Brazilian municipal elections. There is evidence of a downturn in the incumbent's disadvantage between the 2000 and 2008 elections. However, there has been a growth in the phenomenon for the years 2012 and 2016. On the other hand, incumbent governors enjoy a significant advantage of 9.5 points percentages. The advantage of incumbent governors seems to be steadily increasing from 1998 to 2010, when it reaches a maximum of 17.3 percentage points.

Keywords: incumbency advantage, elections, Brazil 


\section{Introdução}

A Emenda Constitucional no 16, de 04 de julho de 1997, mudou as regras do jogo eleitoral brasileiro. Por meio dela, o Congresso Nacional permitiu que os membros do Poder Executivo fossem reeleitos para um período subsequente. Passados quase 22 anos, com cinco eleições municipais e seis eleições estaduais, já há dados suficientes para uma análise sobre os efeitos da introdução desta instituição nas eleições para prefeitos e governadores brasileiros. Uma das primeiras questões levantadas se relaciona à existência, ou não, do fenômeno denominado, pela literatura de economia política, como a vantagem do incumbente. Trata-se de um anglicismo, ainda não amplamente incorporado pelos lexicográficos, que denomina a vantagem que os políticos em exercício do cargo (os incumbentes) obtêm ao tentarem se reeleger.

A vantagem do incumbente parece ser uma hipótese bastante razoável, haja vista os recursos e prerrogativas que dispõem aqueles que exercem o poder. Por exemplo, prefeitos brasileiros possuem discricionariedade sobre o orçamento, o poder de nomear pessoas a cargos governamentais e possibilidades de se fazer propaganda de seus governos. Além disso, tomando-se como premissa que os votantes são, em média, avessos ao risco, faz sentido pensar que o político que já é conhecido e que pode apontar realizações concretas no mandato possui vantagens contra o desafiante, que conta apenas com promessas para tentar se eleger.

No entanto, a literatura mais recente apresenta evidências de que, em países em desenvolvimento, há, na realidade, a existência de uma desvantagem do incumbente. Neste sentido, Uppal (2009) e Linden (2004) estimaram desvantagem do incumbente nas eleições parlamentares da Índia, ao passo que Miguel e Zahidi (2003) não encontraram indícios de vantagem do incumbente na eleição parlamentar de Gana. Macdonald (2014), por sua vez, encontra desvantagem para partidos incumbente em eleições locais na Zâmbia.

Alguns estudos sobre as eleições municipais brasileiras também parecem indicar que prefeitos brasileiros são penalizados pelos eleitores. Titiunik (2011), por exemplo, utiliza partidos políticos como unidade de análise e encontra desvantagem para os partidos 
incumbentes nas eleições de 2000 e 2004. Moreira (2012), utilizando candidatos como unidade de análise, também encontra evidências de desvantagem do incumbente nesses anos, mas vantagem para os incumbentes no ano de 2008. Por outro lado, Magalhães (2012) encontra evidências de uma clara vantagem da incumbência para o ciclo eleitoral de 2004-2008, mas não encontra efeito de incumbência nas probabilidades de reeleição, nos ciclos eleitorais, nos anos de 1996-2000 e 2000-2004.

Por sua vez, Brambor e Ceneviva (2011) utilizam o método de pares repetidos, no qual pares de candidatos a prefeitos que se enfrentam em mais de uma eleição são a unidade de análise. De acordo com os referidos autores, este método é mais apropriado por ser capaz de expurgar tanto os efeitos fixos dos candidatos, como a sua qualidade, quanto os efeitos fixos dos municípios, como suas preferências idiossincráticas. Seu estudo utiliza dados para os anos de 2000, 2004 e 2008, fornecendo evidências de forte desvantagem do incumbente nas eleições municipais brasileiras.

Um dos objetivos deste estudo é o de se aplicar o método de pares repetidos de Brambor e Ceneviva (2011), utilizando-se de uma base de dados mais recente do Tribunal Superior Eleitoral que compreende todas as eleições municipais com possibilidade de reeleição, isto é, de 2000 a 2016. Além disso, sua maior contribuição é realizar a análise para as eleições executivas estaduais brasileiras de 2002 a 2018. A pequena quantidade de estados, comparada aos mais de cinco mil municípios, inviabilizava até então o uso da metodologia que depende de pares de candidatos que se encontram em mais de uma eleição.

Portanto, este trabalho contribui com a literatura ao fornecer uma análise abrangente e atualizada sobre a vantagem do incumbente para as eleições executivas de dois entes federativos brasileiros, os municípios e os estados. Em linha com os principais estudos sobre o assunto, tem-se como hipótese a existência de uma desvantagem do incumbente, tanto para prefeitos como para governadores incumbentes.

Os principais resultados sugerem que prefeitos incumbentes sofrem uma desvantagem de 2,7 pontos percentuais (p.p.) nas eleições municipais brasileiras, confirmando-se a hipótese inicial com uma estimativa muito próxima de Brambor e Ceneviva (2011). No entanto, rejeita-se a hipótese para governadores, uma vez que gozam de uma surpreendente e expressiva vantagem de 9,5 pontos percentuais. 
Com respeito à estrutura do artigo, começa-se com um resumo da literatura vigente sobre a vantagem do incumbente em países em desenvolvimento e especificamente no Brasil. Em seguida, apresenta-se a metodologia desenvolvida por Brambor e Ceneviva (2011) replicada neste estudo, assim como as informações sobre os dados utilizados. Nos resultados, há, em primeiro lugar, uma análise gráfica para dar maior entendimento e intuição sobre o problema, seguida das regressões realizadas. Por fim, conclui-se.

\section{Revisão de literatura}

Os estudos sobre a vantagem do incumbente em países em desenvolvimento têm mostrado que esses candidatos não gozam das mesmas vantagens eleitorais observadas no congresso americano. Estudos de Uppal (2008) e Linden (2004) estimam uma desvantagem do incumbente nas eleições parlamentares da Índia, ao passo que Miguel e Zahidi (2003) encontram efeitos insignificantes de incumbência sobre a probabilidade de se vencer a eleição parlamentar em Gana. Ao estudar as eleições governamentais locais da Zâmbia, Macdonald (2014) encontra uma desvantagem significante para os partidos incumbentes e nenhuma vantagem do incumbente para o nível parlamentar.

As evidências desses estudos geram uma discussão sobre a pertinência do fenômeno de desvantagem do incumbente em países em desenvolvimento. No Brasil, em particular, os municípios possuem grande autonomia política e fiscal (ARRETCHE, 2000), em um arranjo no qual os prefeitos possuem autoridade sobre o orçamento e a nomeação de cargos (BRAMBoR; Ceneviva, 2011). Além disso, há evidências de articulações intrapartidárias importantes, nas quais os resultados das eleições municipais parecem influenciar as eleições legislativas estaduais subsequentes (AVELINO, BIDERMAN; BARONE, 2012).

Tendo em vista os pressupostos de que os eleitores brasileiros não são míopes e premiam ou punem os prefeitos de acordo com sua administração orçamentária e financeira (CAVALCANTE, 2015, FERrAZ; FINAN, 2008; Silva et al., 2013) e que existe uma relação entre a reeleição do governante e o seu comportamento fiscal durante o período das eleições (Meneguin; Bugarin; Carvalho, 2005; Sakural; Menezes-Filho, 2008; ARAúJo Júnior; CANÇADO; SHIKIDA, 2005), as eleições municipais são de especial interesse para se testar essa hipótese. 
Brambor e Ceneviva (2011), por exemplo, ao estudarem as três primeiras eleições municipais brasileiras logo depois da emenda constitucional da reeleição de 1997, estimaram um efeito adverso da incumbência sobre as chances de reeleição, corroborando a hipótese de haver uma desvantagem do incumbente nos países em desenvolvimento. Além disso, o efeito negativo parece diminuir de 2000 a 2008. Os autores utilizaram uma metodologia que leva em consideração apenas encontros repetidos entre candidatos, de modo a se retirar vieses referentes às peculiaridades de cada município e à qualidade dos candidatos. Segundo os autores, as explicações para o efeito de desvantagem da incumbência variam de curtos horizontes temporais, restrições institucionais sobre a reeleição, alta instabilidade econômica ou política a efeitos fiscais.

Em outro estudo sobre as eleições municipais, Titiunik (2011) opta por analisar a vantagem do incumbente ao nível de partidos nas eleições dos anos de 2000 e 2004, encontrando forte evidência de desvantagem do incumbente tanto em proporção de votos quanto em probabilidade de ser reeleito para os três maiores partidos políticos. A autora afirma que tais resultados devem ser interpretados à luz de duas características do sistema político brasileiro: a forte autonomia dos governos subnacionais e a fraca institucionalização do sistema partidário. No contexto de forte instabilidade institucional, horizontes eleitorais curtos e baixos custos de reputação, os incumbentes podem se engajar em rent-seeking, o que resulta em efeitos negativos em futuras eleições.

Por outro lado, Magalhães (2012) apresenta resultados em direção oposta e indica haver vieses de seleção nesses dois estudos brasileiros. O autor argumenta que o estudo de Brambor e Ceneviva (2011) apenas estima o efeito de incumbência em uma subamostra composta por aqueles municípios em que tanto o vencedor quanto o segundo colocado escolhem concorrer novamente. Segundo o autor, essa seleção arbitrária da amostra gera um viés decrescente no efeito estimado da incumbência sobre as probabilidades de reeleição e isso ocorreria porque menos de $50 \%$ dos segundos colocados escolhem concorrer novamente e, aqueles que concorrem novamente, em média, apresentam aumento nos votos, tendo maior probabilidade de serem eleitos em comparação ao incumbente.

Com relação ao estudo de Titiunik (2009), Magalhães (2012) afirma que ele cobre apenas o ciclo eleitoral de 2000-2004 e analisa somente os três maiores partidos da época que pertenciam à coalizão centro-direita liderada pelo partido controlador da presidência, 
o Partido da Social Democracia Brasileira (PSDB). No entanto, essa coalizão perdeu a eleição presidencial de 2002 para o Partido dos Trabalhadores (PT). Isso pode explicar a desvantagem da incumbência nos municípios onde o incumbente pertencia à coalizão do PSDB e o segundo colocado pertencia à coalizão do PT. Além disso, o autor afirma que faz pouco sentido focar a análise em partidos políticos, uma vez que eles tendem a ser fracos no país e os políticos costumam seguir estratégias de campanhas individuais.

Magalhães (2012), por sua vez, não encontra efeito de incumbência nas probabilidades de reeleição nos ciclos eleitorais nos anos de 1996-2000 e 2000-2004. No entanto, encontra evidências de uma clara vantagem da incumbência para o ciclo eleitoral de 2004-2008. Ele enfatiza a pouca capacidade de municípios levantarem recursos próprios, sendo que a maior parcela dos recursos municipais é de transferências federais (em média 65\%). Portanto, seus resultados sugerem que a habilidade de prefeitos serem reeleitos depende do desempenho da economia brasileira e de como os prefeitos são conectados ao Governo Federal.

Ainda sobre as eleições municipais brasileiras, mas adotando a estratégia de regressão com descontinuidade, Moreira (2012) analisa as eleições de 2000 a 2008. Seu estudo indica que a incumbência reduzia as chances de candidatos se reelegerem nas eleições de 2002 e 2004 em 18 e 31 pontos percentuais, respectivamente. Para o ano de 2008 , os cidadãos pararam de penalizar os incumbentes em um período marcado por avanços rápidos nas condições de vida.

Em termos de eleições estaduais, Meneguin e Bugarin (2001) realizaram um estudo econométrico dinâmico (que leva em consideração mais de um período de governo) considerando dois mandatos distintos. O modelo se baseou em uma regressão para estudar o grau de associação linear entre a despesa total do governo em ano eleitoral e o fato de o referido governo ter ou não permanecido no poder. Dessa forma, o modelo indica que a reeleição acaba sendo uma boa maneira de controle de gastos e incentiva a responsabilidade fiscal por parte do governante. Tal resultado sugeriria uma maior cautela por parte dos governadores, o que poderia sinalizar uma premiação por parte do eleitorado, ou seja, maiores vantagens para os candidatos incumbentes.

A capacidade de premiação dos eleitores é um dos resultados de Libanio e MenezesFilho (2003) em sua análise sobre o fenômeno da reeleição dos governadores brasileiros. 
O estudo sugere que eleitores percebem a melhora nos indicadores sociais como sinalizadora de qualidade da gestão pública, de forma a recompensar os incumbentes com maiores probabilidades de reeleição. Destaca-se que, enquanto o aumento da pobreza influencia negativamente a permanência no poder, a desigualdade de renda não exerce qualquer influência.

Ainda se tratando de estados brasileiros, Nakaguma e Bender (2010) investigaram as causas determinantes da existência de ciclos eleitorais na política fiscal. Seus resultados sugerem ciclos políticos bem definidos, com fortes elevações durante os anos eleitorais e quedas nos anos subsequentes. Desse modo, a proporção de votos do governador incumbente responde positivamente por manipulações oportunistas nas despesas e receitas orçamentárias. Tal resultado pode ser interpretado como falta de controle político dos eleitores induzindo a produção dos ciclos. Entretanto, o coeficiente da regressão apresenta tendência de queda ao longo do tempo, o que poderia indicar que o aumento da experiência dos eleitores com o processo eleitoral melhora a capacidade de identificarem e punirem manipulações eleitorais.

\section{Metodologia e dados}

\subsection{Metodologia de pares repetidos}

Este estudo utiliza a mesma metodologia desenvolvida por Brambor e Ceneviva (2011) no artigo sobre a vantagem do incumbente nas eleições municipais brasileiras, cuja abordagem de pares repetidos foi previamente utilizada por Levitt (1994) em seus estudos sobre os efeitos de gastos de campanha nas chances de reeleição na Câmara dos Representantes americana, e por Levitt e Wolfram (1997) ao analisarem a vantagem do incumbente nessa mesma câmara.

O primeiro passo é modelar a proporção de votos, $V_{i k}^{t}$, de um candidato $k$ em uma dada eleição $t$ para o cargo executivo do município $i$, como sendo:

$$
V_{i k}^{t}=\alpha_{k}+\beta I_{i k}^{t}+\theta_{i t}+e_{i k}^{t}
$$

onde $\alpha_{k}$ representa os efeitos fixos específicos do candidato, isto é, uma medida das 
características fixas do candidato como sua qualidade ou força. O segundo termo, $I_{i k}^{t}$, é um indicador de incumbência, o que torna $\theta_{i t}$ a quantidade de interesse ao medir a vantagem do incumbente. O terceiro termo, $\beta$, se refere aos efeitos fixos específicos do município e varia com o tempo. De acordo com os autores, $\theta_{i t}$ captura tanto as mudanças na arena política nacional quanto para cada município. Por fim, $e_{i k}^{t}$ é o termo de erro.

Como a metodologia se baseia em encontros de candidatos, os autores sugerem uma primeira diferenciação, ao levar em consideração a proporção de votos de dois candidatos em uma eleição específica no ano $t$ :

$$
\begin{gathered}
V_{i 1}^{t}=\alpha_{1}+\beta I_{i 1}^{t}+\theta_{i}+e_{i 1}^{t} \\
V_{i 2}^{t}=\alpha_{2}+\beta I_{i 2}^{t}+\theta_{i}+e_{i 2}^{t} \\
\Delta V_{i}^{t}=V_{i 1}^{t}-V_{i 2}^{t}=\left(\alpha_{1}-\alpha_{2}\right)+\beta\left(I_{i 1}^{t}-I_{i 2}^{t}\right)+v_{i}^{t}
\end{gathered}
$$

A equação (4), portanto, representa a diferença de votos entre um par de candidatos. Observa-se que nela não se apresenta o efeito específico do município, uma vez que a disputa ocorreu em um mesmo município, mas ainda leva em consideração a diferença de qualidade dos candidatos.

Com o intuito de se retirar o efeito da qualidade dos candidatos, dada a dificuldade de se medir tal variável, segue-se com uma segunda diferenciação, agora focada em pares de candidatos que se reencontram em eleições distintas:

$$
\begin{aligned}
& \mathrm{Em} \mathrm{t}=1: \Delta V_{i}^{1}=V_{i 1}^{1}-V_{i 2}^{1}=\left(\alpha_{1}-\alpha_{2}\right)+\beta\left(I_{i 1}^{1}-I_{i 2}^{1}\right)+v_{i}^{1} \\
& \mathrm{Em} \mathrm{t}=2: \Delta V_{i}^{1}=V_{i 1}^{2}-V_{i 2}^{2}=\left(\alpha_{1}-\alpha_{2}\right)+\beta\left(I_{i 1}^{2}-I_{i 2}^{2}\right)+v_{i}^{2} \\
& \Delta V_{i}=V_{i 1}^{1}-V_{i 2}^{2}=\beta\left[\left(I_{i 1}^{1}-I_{i 2}^{1}\right)-\left(I_{i 1}^{2}-I_{i 2}^{2}\right)\right]+\left(v_{i}^{1}-v_{i}^{2}\right)
\end{aligned}
$$

Assim, após duas etapas de diferenciação, obtém-se a equação (7), que representa a diferença da diferença de votos entre um par de candidatos em duas eleições distintas, dependendo apenas da situação de incumbência dos candidatos durante estas eleições, e os termos de erro. A quantidade de interesse, $\beta$, continua medindo a vantagem da incumbência. 
Tabela 1 | Possíveis combinações de incumbência para pares repetidos

\begin{tabular}{|c|c|c|c|c|c|}
\hline & \multicolumn{4}{|c|}{ O candidato é incumbente? } & Diferença da diferença \\
\hline & \multicolumn{2}{|c|}{$t=1$} & \multicolumn{2}{|c|}{$t=2$} & \multirow[b]{2}{*}{$\underline{\left[\left(I_{i 1}^{1}-I_{i 2}^{2}\right)-\left(I_{i 1}^{1}-I_{i 2}^{2}\right)\right]}$} \\
\hline caso & cand 1 & cand 2 & cand 1 & cand 2 & \\
\hline \multicolumn{6}{|c|}{ Pares informativos } \\
\hline la & Não & não & não & $\operatorname{sim}$ & $(0-0)-(0-1)=1$ \\
\hline $\mathrm{lb}$ & Não & não & $\operatorname{sim}$ & não & $(0-0)-(1-0)=-1$ \\
\hline Ila & Sim & não & não & não & $(1-0)-(0-0)=1$ \\
\hline $\mathrm{IIb}$ & Não & $\operatorname{sim}$ & não & não & $(0-1)-(0-0)=-1$ \\
\hline Illa & Não & $\operatorname{sim}$ & $\operatorname{sim}$ & não & $(0-1)-(1-0)=-2$ \\
\hline IIIb & Sim & não & não & $\operatorname{sim}$ & $(1-0)-(0-1)=2$ \\
\hline \multicolumn{6}{|c|}{ Pares não informativos } \\
\hline & Não & não & não & não & $(0-0)-(0-0)=0$ \\
\hline & Não & $\operatorname{sim}$ & não & $\operatorname{sim}$ & $(0-1)-(0-1)=0$ \\
\hline & Sim & não & $\operatorname{sim}$ & não & $(1-0)-(1-0)=0$ \\
\hline
\end{tabular}

Fonte: Brambor e Ceneviva (2011).

Para que a estimação de $\beta$ seja possível, o segundo termo da equação (7), $\left[\left(I_{i 1}^{1}-I_{i 2}^{2}\right)-\left(I_{i 1}^{1}-I_{i 2}^{2}\right)\right]$, que representa a situação de incumbência dos candidatos durante as duas eleições diferentes, não pode ser igual a zero. A limitação da legislação eleitoral, de possibilidade de apenas uma vez de reeleição, fornece três casos em que este termo não é igual a zero, ou seja, casos informativos, e três casos não informativos. A Tabela 1 apresenta tais casos.

Para facilitar a compreensão dos casos informativos, optou-se por dividi-los em duas versões, (a) e (b). A distinção entre eles é apenas a ordem dos candidatos. O caso $I$ representa os pares em que nenhum dos candidatos era o incumbente na primeira eleição e, na segunda eleição, um deles é o incumbente. No caso $I I$, um dos candidatos é o incumbente na primeira eleição, enquanto nenhum deles o é na segunda eleição. O caso III engloba os pares em que na primeira eleição um dos candidatos era o incumbente, e na segunda eleição o outro candidato se torna o incumbente. A parte inferior da tabela apresenta os casos em que a disposição de incumbência dos candidatos nas eleições não permite a estimação de . 


\subsection{Base de dados}

Os dados utilizados neste estudo foram obtidos através do Repositório de Dados Eleitorais no endereço eletrônico do Tribunal Superior Eleitoral (2018). Para as cinco eleições municipais levadas em consideração neste estudo, foram observados 75793 candidatos concorrendo ao cargo de prefeito em 5564 municípios diferentes, cuja média de proporção de votos por candidato foi de 33,4\%. Já para as seis eleições estaduais, foram observados 1232 candidatos concorrendo ao cargo de governador em 26 estados e o Distrito Federal. A média de proporção de votos por candidato, neste caso, foi de $21,4 \%$.

Tabela 2 | Distribuição de pares de candidatos a prefeito em casos informativos

\begin{tabular}{lccccc}
\multicolumn{5}{c}{ Há quantas eleições o par se encontrou pela } \\
\multicolumn{7}{c}{ última vez? } \\
\hline Caso & 1 & 2 & 3 & 4 & Total \\
\hline la/b & 3102 & 567 & 154 & 35 & 3858 \\
\hline Ila/b & 102 & 135 & 31 & 0 & 268 \\
\hline Illa/b & 561 & 191 & 10 & 0 & 762 \\
\hline Total & 3765 & 893 & 195 & 35 & 4888 \\
\hline
\end{tabular}

Fonte: elaboração própria.

As distribuições de casos informativos para a análise de eleições municipais e estaduais encontram-se, respectivamente, nas Tabelas 2 e 3 . Para os dois entes federativos, o caso la/b, em eleições consecutivas, apresentou a grande maioria de pares repetidos. Este é o caso em que o primeiro encontro acontece quando nenhum candidato é incumbente, um deles ganha a eleição e se enfrentam na eleição seguinte em que um deles é o incumbente. Nota-se, também, uma tendência de, quanto maior o período intermitente entre uma eleição e a outra, menor a probabilidade de se encontrar pares repetidos.

Tabela 3 | Distribuição de pares de candidatos a governador em casos informativos

Há quantas eleições o par se encontrou pela última vez?

\begin{tabular}{lcccccc} 
Caso & 1 & 2 & 3 & 4 & 5 & Total \\
\hline $\mathrm{la} / \mathrm{b}$ & 30 & 2 & 1 & 2 & 0 & 35 \\
\hline $\mathrm{Ila} / \mathrm{b}$ & 2 & 5 & 1 & 2 & 0 & 10 \\
\hline $\mathrm{IIla} / \mathrm{b}$ & 4 & 2 & 0 & 0 & 0 & 6 \\
Total & 36 & 9 & 2 & 4 & 0 & 51
\end{tabular}

Fonte: elaboração própria. 
As Tabelas 4 e 5 apresentam as estatísticas descritivas para algumas das variáveis de interesse das análises de prefeitos e governadores, respectivamente. Neste momento, torna-se importante frisar que a unidade de análise dos dados é o candidato por ano de eleição. Consequentemente, alguns candidatos, principalmente aqueles dos pares repetidos, aparecem mais de uma vez.

Tabela 4 | Estatística descritiva de candidatos a prefeito em pares repetidos vs. pares não repetidos (2000-2016)

\begin{tabular}{lcccccc} 
Variável & Níveis de amostra & $\mathrm{n}$ & Média & Mediana & Mín. & Máx. \\
Eleito & Pares repetidos & 19623 & 0,46 & 0 & 0 & 1 \\
\hline & Não repetidos & 56170 & 0,33 & 0 & 0 & 1 \\
\hline Votos no município & Todos & 75793 & 0,36 & 0 & 0 & 1 \\
\hline & Pares repetidos & 19623 & 16074 & 7990 & 599 & 515362 \\
\hline Võo repetidos & 56170 & 22391 & 7333 & 450 & 6494140 \\
\hline & Todos & 75793 & 20755 & 7498 & 450 & 6494140 \\
\hline Proporção de votos por candidato & Pares repetidos & 19623 & 5981 & 3023 & 0 & 288821 \\
\hline & Não repetidos & 56170 & 4914 & 1971 & 0 & 4195466 \\
\hline & Pares repetidos & 19623 & 0,42 & 0.45 & 0 & 4195466 \\
\hline & Não repetidos & 56170 & 0,35 & 0,39 & 0 & 1 \\
\hline
\end{tabular}

Fonte: elaboração própria.

Tabela 5 | Estatística descritiva de candidatos a governador em pares repetidos vs. pares não repetidos (1998-2018)

\begin{tabular}{lcccccc} 
Variável & Níveis de amostra & $\mathrm{n}$ & Média & Mediana & Mín. & Máx. \\
Eleito & Pares repetidos & 188 & 0,39 & 0 & 0 & 1 \\
\hline & Não repetidos & 1066 & 0,11 & 0 & 0 & 1 \\
\hline \multirow{2}{*}{ Votos no estado } & Todos & 1254 & 0,15 & 0 & 0 & 1 \\
\hline & Pares repetidos & 188 & 3692152 & 2628831 & 125050 & 22769983 \\
\hline & Não repetidos & 1066 & 3821346 & 1893926 & 62823 & 22769983 \\
\hline Votos por candidato & Todos & 1254 & 3801977 & 1900486 & 62823 & 22769983 \\
\hline & Pares repetidos & 188 & 1128676 & 488276 & 715 & 12230807 \\
\hline & Não repetidos & 1066 & 381909 & 51566 & 0 & 12381038 \\
\hline Proporção de votos & Todos & 1254 & 493864 & 74527 & 0 & 12230807 \\
\hline & Pares repetidos & 188 & 0,31 & 0,33 & 0 & 0,83
\end{tabular}

Fonte: elaboração própria. 


\section{Resultados}

\subsection{Eleições municipais}

Usando os dados de pares repetidos nas eleições municipais brasileiras de 2000 a 2016 e de acordo com a equação (7), foi possível obter os resultados apresentados nas Tabelas 6 e 7. Na coluna 1, observa-se que o efeito estimado de incumbência para as eleições municipais foi de 2,7 pontos percentuais negativos. Um valor praticamente idêntico ao estimado por Brambor e Ceneviva (2011).

A coluna 2 apresenta os resultados quando acrescentadas dummies indicando o ano em que o par de candidato se encontrou pela segunda vez. Para pares de candidatos que se encontraram pela primeira vez em 2000 e depois em 2004, o incumbente sofreu uma grande desvantagem de 9,3 pontos percentuais. Não foi possível afirmar algo sobre o efeito de incumbência para o ano de 2008. Entretanto, para os de 2012 e 2016, estimouse desvantagens para o incumbente de -1,3 e -4,9 pontos percentuais, respectivamente. Brambor e Ceneviva (2011) haviam estimado uma dinâmica parecida, de grande desvantagem do incumbente em 2000 (-9,4), menor desvantagem em 2004 (-4,3) e uma pequena vantagem do incumbente para o ano de $2008(+2,0)$. Os autores suspeitam que essa tendência de queda do efeito negativo da incumbência poderia ser, pelo menos em parte, atribuída ao ânimo durante o crescimento extraordinário da economia no governo Lula (2003-2010). Assim, o tratamento mais desfavorável dos votantes para os anos de 2012 e 2016, estimado agora, também parece ser, em parte, consequência das turbulências econômicas e políticas durante o governo Dilma (2011-2016).

A coluna 3 apresenta a regressão na qual são utilizadas dummies para casos em que as eleições são consecutivas ou não. Para os pares em que as eleições foram consecutivas, estimou-se um grande efeito negativo de incumbência de $-6,3$ pontos percentuais, enquanto, para os pares que não se encontraram na última eleição, estimou-se uma vantagem para o incumbente de 8 pontos percentuais. Tais resultados são consistentes com os de Brambor e Ceneviva (2011) e com a análise visual realizada anteriormente. Os autores levantam a hipótese de que os candidatos que optam por não concorrer em uma eleição seguida sofrem por isso, dada a dificuldade de votantes lembrarem-se de 
um candidato que concorreu oito ou mais anos atrás. Os incumbentes, que por definição concorrem em eleições consecutivas, devem ter maior facilidade de convencer os votantes de suas qualidades para serem reeleitos. Se isso for verdade, é de se esperar que, quanto maior o hiato temporal da ausência em eleições, maior o efeito positivo de incumbência.

A regressão apresentada na coluna 1 da Tabela 7 tenta entender tal interação ao utilizar dummies indicando quantas eleições separam o primeiro e o segundo encontro dos candidatos. Assim como Brambor e Ceneviva (2011), estimou-se uma desvantagem para incumbentes quand o o par se encontra em eleições consecutivas. Para os casos em que há um hiato de uma ou duas eleições, encontrou-se um efeito positivo de incumbência de 8,2 e 7,9 pontos percentuais. Tais resultados são, no entanto, menores que os encontrados por Brambor e Ceneviva (2011).

Por fim, na coluna 2 da Tabela 7, é apresentada a regressão com dummies para os diferentes casos de pares informativos da Tabela 1. Para o caso la/b e Ila/b, estimou-se uma desvantagem para o incumbente de $-5,2$ e -1,2 pontos percentuais, respectivamente. $\mathrm{O}$ caso Ila/b, por outro lado, apresentou uma grande vantagem para o incumbente de 10,4 pontos percentuais.

Uma vez estimado o efeito da incumbência geral para os municípios brasileiros, restou a pergunta se tal efeito varia muito entre os estados brasileiros. Por isso, repetiuse a mesma estimação considerando todos os municípios de cada estado. Os resultados estão resumidos na Figura 1, onde se encontra, para cada estado, a representação gráfica da estimativa do efeito de incumbência de prefeitos e seu intervalo de confiança de $95 \%$. Como a quantidade de municípios por estado varia muito, os intervalos de confiança são bem variados, de modo a inviabilizar a conclusão sobre sua pertinência em muitos estados. No entanto, nota-se que, para a grande maioria dos estados, o efeito da incumbência é negativo. Roraima apresentou uma forte desvantagem do incumbente de $-8,6$ p.p., enquanto São Paulo é, daqueles em que se pôde fazer inferência, o que apresenta menor desvantagem do incumbente para prefeitos, com -2,5 pontos percentuais. 
Tabela 6 | Pares repetidos - os efeitos da incumbência sobre o percentual de votos nas eleições municipais brasileiras (2000-2016)

Pares repetidos - os efeitos da incumbência sobre o percentual de votos nas eleições municipais brasileiras (2000-2016)

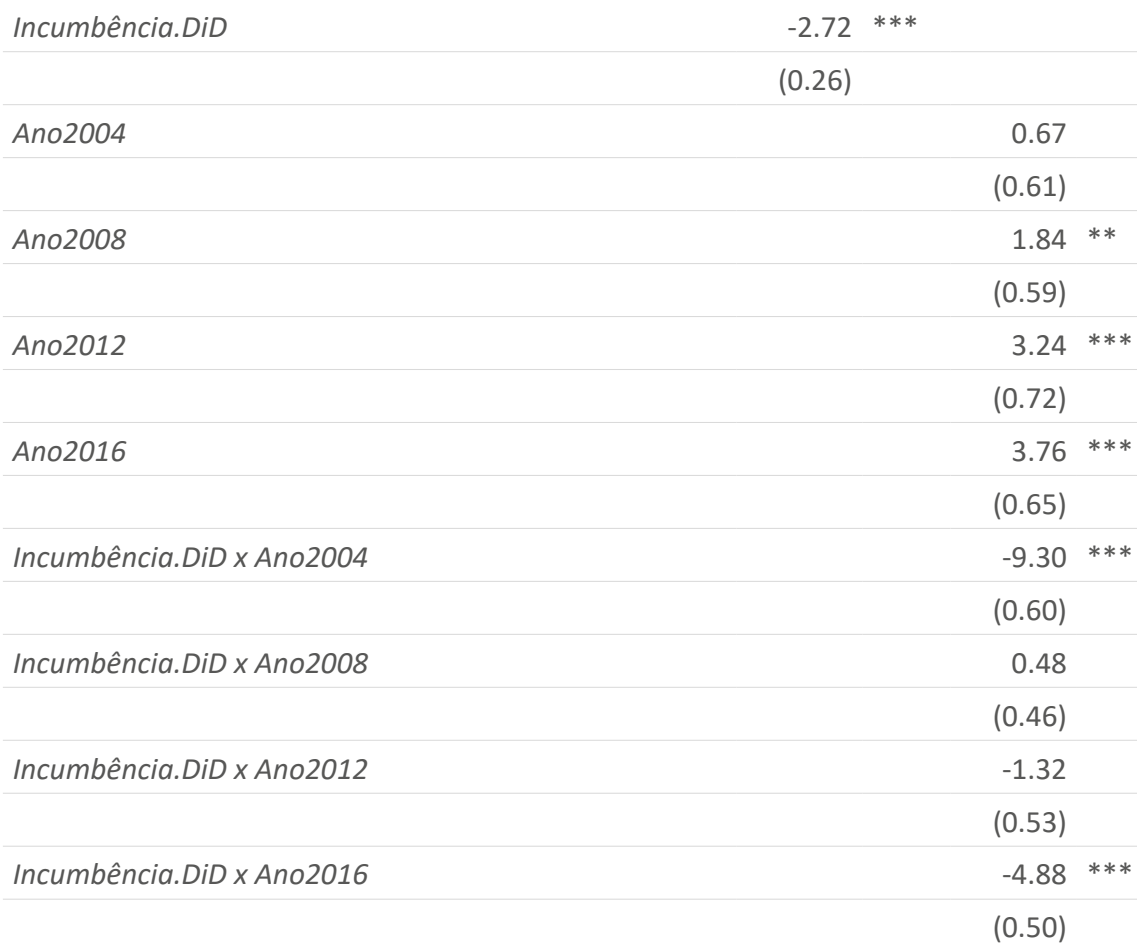

Não se encontraram na última eleição

(0.34)

Se encontraram na última eleição

0.84

(0.72)

Incumbência.DiD x Não se encontraram na última eleição

Incumbência.DiD x Se encontraram na última eleição

Número de obs.

4888

4888 4888

R2 Ajustado

0.0202

0.0638

0.1321

${ }^{*} p<0.05, * * p<0.01, * * * p<0.001$

Fonte: elaboração própria. 
Tabela 7 | Pares repetidos - os efeitos da incumbência sobre o percentual de votos nas eleições municipais brasileiras (2000-2016)

Pares repetidos - os efeitos da incumbência sobre o percentual de votos nas eleições municipais brasileiras (2000-2016)

\begin{tabular}{|c|c|c|c|c|}
\hline \multirow[t]{2}{*}{ ÚltimoEncontro (t-1) } & 2.46 & $* * *$ & & \\
\hline & $(0.34)$ & & & \\
\hline \multirow[t]{2}{*}{ ÚltimoEncontro (t-2) } & 0.28 & & & \\
\hline & $(0.79)$ & & & \\
\hline \multirow[t]{2}{*}{ ÚltimoEncontro (t-3) } & 2.83 & & & \\
\hline & (1.86) & & & \\
\hline \multirow[t]{2}{*}{ ÚltimoEncontro (t-4) } & 0.35 & & & \\
\hline & $(4.90)$ & & & \\
\hline \multirow[t]{2}{*}{ Incumbência.DiD x ÚltimoEncontro (t-1) } & -6.33 & $* * *$ & & \\
\hline & $(0.28)$ & & & \\
\hline \multirow[t]{2}{*}{ Incumbência.DiD x ÚltimoEncontro (t-2) } & 8.25 & $* * *$ & & \\
\hline & $(0.60)$ & & & \\
\hline \multirow[t]{2}{*}{ Incumbência.DiD x ÚltimoEncontro (t-3) } & 7.96 & $* * *$ & & \\
\hline & (1.76) & & & \\
\hline \multirow[t]{2}{*}{ Incumbência.DiD x ÚltimoEncontro (t-4) } & -0.77 & & & \\
\hline & $(4.90)$ & & & \\
\hline \multirow[t]{2}{*}{ Caso la/b } & & & 1.63 & $* * *$ \\
\hline & & & $(0.36)$ & \\
\hline \multirow[t]{2}{*}{ Caso Ila/b } & & & 0.98 & \\
\hline & & & $(1.94)$ & \\
\hline \multirow[t]{2}{*}{ Caso IIIa/b } & & & 2.75 & $* * *$ \\
\hline & & & $(0.82)$ & \\
\hline \multirow[t]{2}{*}{ Incumbência x Caso la/b } & & & -5.28 & $* * *$ \\
\hline & & & $(0.36)$ & \\
\hline \multirow[t]{2}{*}{ Incumbência x Caso I/a/b } & & & 10.49 & $* * *$ \\
\hline & & & $(1.94)$ & \\
\hline \multirow[t]{2}{*}{ Incumbência x Caso IIIa/b } & & & -1.27 & $* *$ \\
\hline & & & $(0.41)$ & \\
\hline Número de obs. & 4888 & & 4888 & \\
\hline R2 Ajustado & 0.1328 & & 0.0603 & \\
\hline$* p<0.05, * * p<0.01, * * * p<0.001$ & & & & \\
\hline
\end{tabular}

Fonte: elaboração própria. 
Figura 1 - Efeito da incumbência por estado

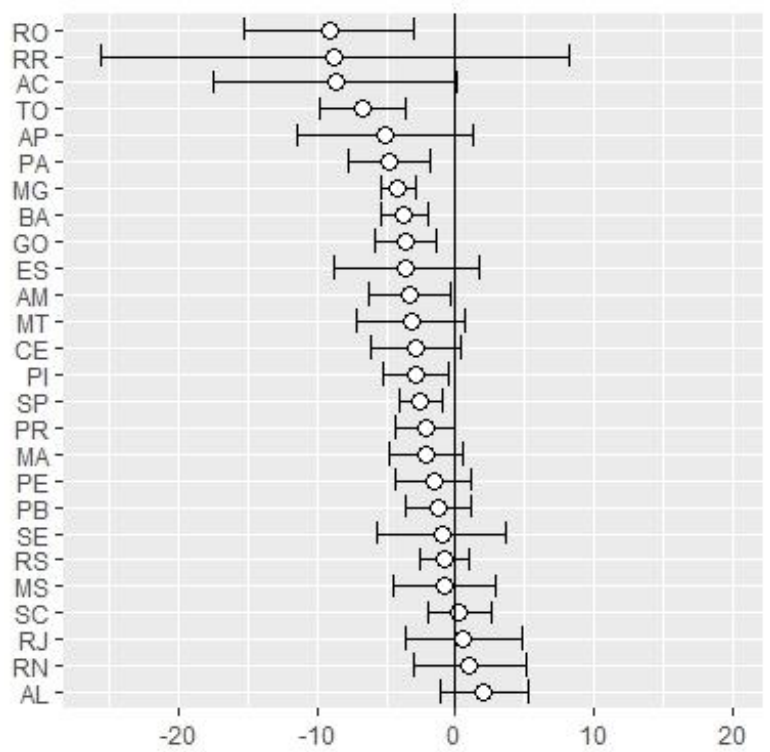

Fonte: elaboração própria.

\subsection{Eleições estaduais}

As Tabelas 8 e 9 apresentam os resultados das regressões para os dados de pares repetidos das eleições estaduais brasileiras de 1998 a 2018. Se prefeitos incumbentes enfrentam, em média, uma desvantagem de $-2,7$ pontos percentuais, por outro lado, os governadores incumbentes gozam de uma significante vantagem de 9,5 pontos percentuais.

A coluna 2 da Tabela 8 mostra a regressão com dummies que tentam captar a variação do fenômeno no tempo. Neste caso, teve-se que omitir as variáveis que isolavam o efeito de incumbência para os anos de 1998 e 2008, uma vez que apresentavam multicolinearidade com as variáveis dos respectivos anos. A regressão nos informa que os governadores incumbentes têm apresentado expressiva vantagem em quase todas as eleições. A vantagem de governadores em exercício do cargo parece manter trajetória crescente de 1998 até 2010, quando atinge o máximo de 17,3 pontos percentuais. Em 2010 ela cai para 8,5 pontos percentuais.

Independentemente de o par de candidatos se encontrar em eleições seguidas ou não, o governador incumbente apresenta vantagem (coluna 3 da Tabela 8). No entanto, 
a vantagem para governadores incumbentes em pares que se encontram em eleições seguidas é de apenas 6,6 pontos percentuais, enquanto, para os pares com maior hiato temporal entre o primeiro e segundo encontro, a vantagem sobe para significativos 17,8 pontos percentuais. Tal resultado sugere que os governadores não incumbentes que deixam de participar de eleições seguidas são ainda mais penalizados do que os prefeitos nessa situação.

Tabela 8 | Pares repetidos - os efeitos da incumbência sobre o percentual de votos nas eleições estaduais brasileiras (1998-2018)

Pares repetidos - os efeitos da incumbência sobre o percentual de votos nas eleições estaduais brasileiras (1998-2018)

Incumbência.DiD

Ano1998

$(12.10)$

Ano2002

13.18

(8.04)

Ano2006

6.07

(7.64)

Ano2010

21.93

(7.04)

Ano2014

0.05

(4.21)

Ano2018

$26.78 * * *$

(4.48)

Incumbência.DiD x Ano2002

4.24

(8.04)

Incumbência.DiD x Ano2006

13.11

(5.64)

Incumbência.DiD x Ano2010

$17.38 * * *$

$(4.48)$

Incumbência.DiD x Ano2014 
Pares repetidos - os efeitos da incumbência sobre o percentual de votos nas eleições estaduais brasileiras (1998-2018)

Não se encontraram na última eleição

Se encontraram na última eleição

Incumbência.DiD x Não se encontraram na última eleição

Incumbência.DiD x Se encontraram na última eleição $17.81^{* *}$

$(5.60)$

Número de obs.

51

51

51

$\begin{array}{llll}\text { R2 Ajustado } & 0.2477 & 0.3392 & 0.3087\end{array}$

$* p<0.05, * * p<0.01, * * * p<0.001$

Fonte: elaboração própria.

Tabela 9 | Pares repetidos - os efeitos da incumbência sobre o percentual de votos nas eleições estaduais brasileiras (1998-2018)

Pares repetidos - os efeitos da incumbência sobre o percentual de votos nas eleições estaduais brasileiras (1998-2018)

ÚltimoEncontro (t-1) $\quad 5.18$

ÚltimoEncontro (t-2) $\quad 10.41$

(13.61)

ÚltimoEncontro (t-3) $\quad 10.57$

(0.00)

ÚltimoEncontro (t-4) $\quad 0.84$

(4.64)

Incumbência.DiD x ÚltimoEncontro (t-1) $6.61 *$

(2.53)

Incumbência.DiD x ÚltimoEncontro (t-2) 16.77

(9.93)

Incumbência.DiD x ÚltimoEncontro (t-3)

$26.45^{* * *}$

(0.00)

Incumbência.DiD x ÚltimoEncontro (t-4)

16.91 


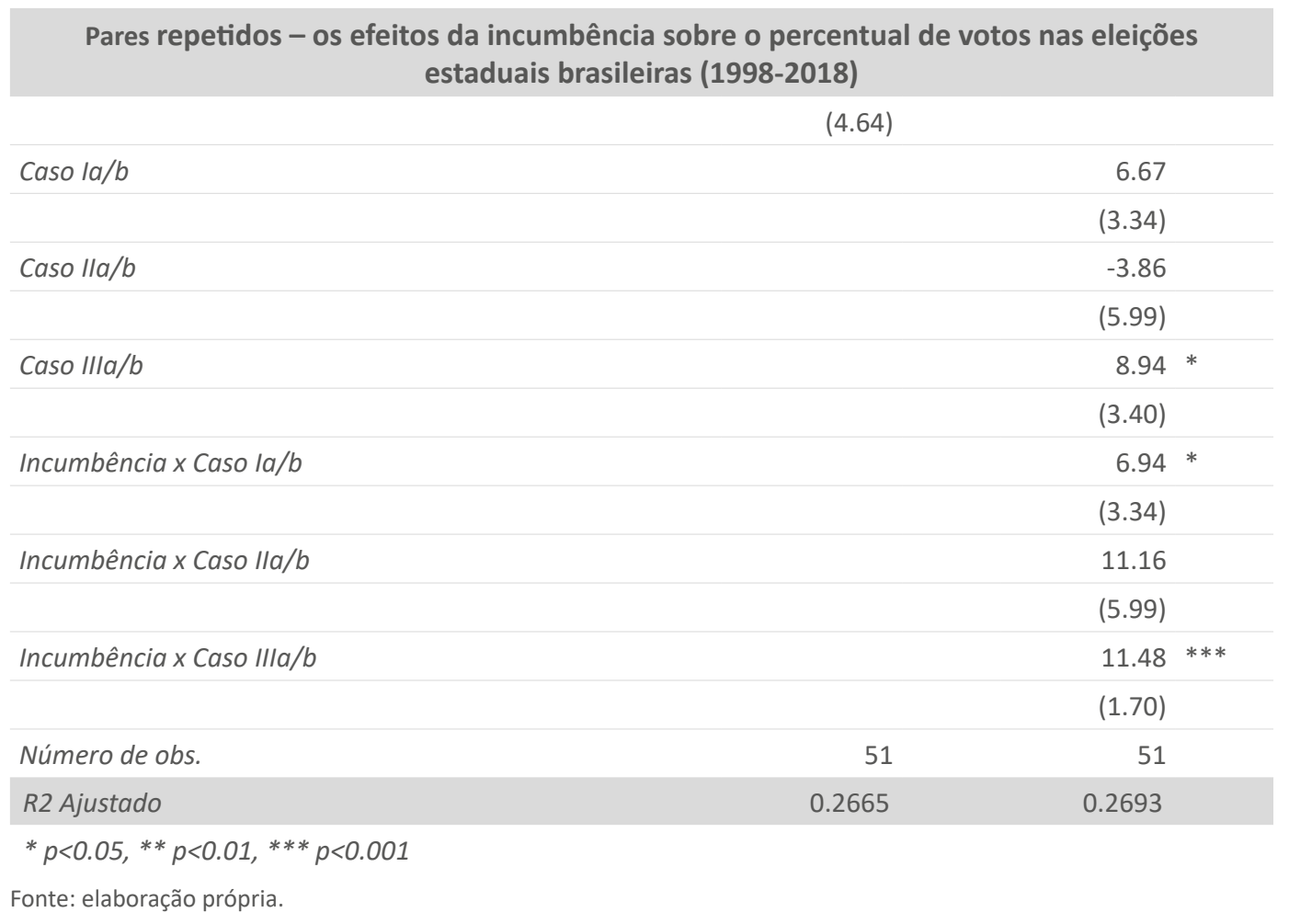

\section{Conclusão}

Este trabalho teve como objetivo a verificação empírica de ocorrência da vantagem do incumbente em eleições estaduais e municipais brasileiras. Utilizou-se o mesmo método de pares repetidos de Brambor e Ceneviva (2011), no qual pares de candidatos que se enfrentam mais de uma vez são a unidade de análise. A grande vantagem de utilizá-lo reside na retirada de efeitos fixos de candidato e município. Ou seja, possíveis vieses relacionados à omissão de qualidades específicas de candidatos e de preferências específicas de municípios deixam de ser um problema.

Especificamente, o estudo estimou que prefeitos incumbentes sofrem uma desvantagem de 2,7 pontos percentuais nas eleições municipais brasileiras. Há evidências de queda na desvantagem do incumbente entre as eleições de 2000 e 2008, no entanto observa-se um crescimento do fenômeno para os anos de 2012 e 2016. Em contrapartida, os governadores gozam de uma expressiva vantagem de 9,5 pontos percentuais. Essa 
vantagem parece manter trajetória crescente de 1998 até 2010, quando atinge o máximo de 17,3 pontos percentuais.

Portanto, este trabalho apresenta características contrastantes em termos de vantagem do incumbente para eleições executivas de dois entes federativos brasileiros. Corrobora-se a evidência de outros estudos da literatura sobre a desvantagem com que prefeitos incumbentes se deparam ao tentarem se reeleger. Por outro lado, constata-se que governadores incumbentes brasileiros se beneficiam com ampla vantagem. Os estudos recentes em países em desenvolvimento tendem a verificar a existência de desvantagem ou vantagem do incumbente em um determinado nível governamental. Mostra-se, então, que não se pode estender uma evidência - muitas vezes única - em um determinado nível governamental para o país inteiro.

Essas diferenças fornecem uma excelente oportunidade para que trabalhos futuros encontrem os determinantes dos efeitos de incumbência, de modo a elucidar o fenômeno em países em desenvolvimento. Quais seriam as diferenças institucionais que balizam as ações de prefeitos comparativamente aos governadores que os levam a ser penalizados ao tentarem se reeleger? Os governadores estão sujeitos a incentivos para ter melhor desempenho? O simples fato de eleições executivas estaduais ocorrerem juntamente com a eleição do Presidente da República afeta o resultado?

\section{Referências bibliográficas}

ARAújo Júnior, A. F.; CANÇADO, P. L.; SHIKIDA, C. D. Economics and politics: o que determina as chances de reeleição em municípios? O caso das eleições municipais de Minas Gerais - 2000. Informe Gepec, v. 9, n. 2, p. 1-19, 2005.

ARretche, M. T. S. Políticas sociais no Brasil: descentralização em um Estado federativo. Revista Brasileira de Ciências Sociais, v. 14, n. 40, p. 111-141, 1999.

AVELINO, G.; BIDERMAN, C.; BARONE, L. S. Intra-partisan linkage and electoral performance in Brazil. Dados, v. 55, n. 4, p. 987-1013, 2012.

BRAmbor, T.; Ceneviva, R. Incumbency advantage in Brazilian mayoral elections. Working Paper, 2011. Disponível em: https://ssrn.com/abstract=1903410

CAVALCANTE, Pedro. Vale a pena ser um bom prefeito? Comportamento eleitoral e reeleição no Brasil. Opinião Pública, v. 21, n. 1, p. 87-104, 2015. 
FERRAZ, C.; FInAN, F. Exposing corrupt politicians: the effects of Brazil's publicly released audits on electoral outcomes. The Quarterly Journal of Economics, v. 123, n. 2, p. 703-745, 2008.

LEVITT, Steven D. Using repeat challengers to estimate the effect of campaign spending on election outcomes in the US House. Journal of Political Economy, v. 102, n. 4, p. 777-798, 1994.

LEVITT, S. D.; Wolfram, C. D. Decomposing the sources of incumbency advantage in the US House. Legislative Studies Quarterly, v. 22, n. 1, p. 45-60, 1997.

LIBANIO, R. C.; MENEZES-FILHO, N. Indicadores sociais e desempenho nas eleições estaduais. In: Encontro Nacional de Economia, 31., 2003, Porto Seguro. Anais... Porto Seguro: Anpec, 2003.

LINDEN, L. Are incumbents really advantaged? The preference for non-incumbents in Indian national elections. Unpublished paper, 2004.

MACDONALD, B. Incumbency disadvantages in African politics? Regression discontinuity evidence from Zambian elections. Unpublished paper, 2014.

MAGALHÃES, L. M. Incumbency effects in Brazilian mayoral elections: a regression discontinuity design. Centre for Market and Public Organisation, Working Paper n. 12, p. 284, 2012.

Meneguin, F. B.; BUgARIN, M. S. Reeleição e política fiscal: um estudo dos efeitos da reeleição nos gastos públicos. Economia Aplicada, v. 5, n. 3, p. 601-622, 2001.

Meneguin, F. B.; Bugarin, M. S.; Carvalho, A. X. de. Que leva um governante à reeleição? Brasília, Textos para Discussão Ipea, n.1135, 2005.

MIGUEL, E.; ZAIDI, F. Do politicians reward their supporters? Regression discontinuity evidence from Ghana. Working Paper, University of California Berkeley, 2003.

MoreIRA, M. G. R. Are Incumbents advantaged? Evidence from Brazilian municipalities using a quasi-experimental approach. In: MeETING OF THE BRAZILIAN ECONOMETRIC SOCIETY, 34., 2012, Rio de Janeiro. Anais... Rio de Janeiro: SBE, 2012.

NAKAGUMA, M. Y.; BENDER, S. Ciclos políticos e resultados eleitorais: um estudo sobre o comportamento do eleitor brasileiro. Revista Brasileira de Economia, v. 64, n. 1, p. 3-24, 2010.

SAKURAi, S. N.; Menezes-Filho, N. A. Fiscal policy and reelection in Brazilian municipalities. Public Choice, v. 137, n. 1-2, p. 301-314, 2008.

Silva, F. L. M.; VASSelai, F.; LUCCA-Silveira, M. P.; MAgalhães, R. N.; SIMONI JR., S. Programa Bolsa-Família e a performance eleitoral dos incumbentes municipais. In: SEMINÁRIO DISCENTE DA Pós-Graduação em CIÊnCIA PolítICA DA USP, 3., 2013, São Paulo. Anais... São Paulo: USP, 2013.

TITIUNIK, R. Incumbency advantage in Brazil: evidence from municipal mayor elections. Working Paper, 2011. Disponível em: http://www-personal.umich.edu/ titiunik/papers/Titiunik_IABrazil. pdf

Tribunal SUPERIOR Eleitoral (TSE). Repositório de dados eleitorais. 2018. Disponível em: <http:// www.tse.jus.br/eleicoes/estatisticas/repositorio-de-dados-eleitorais-1/repositorio-de-dados-eleitorais> Acesso em 20 jul. 2018.

UPPAL, Y. The disadvantaged incumbents: estimating incumbency effects in Indian state legislatures. Public Choice, v. 138, n. 1-2, p. 9-27, 2009. 
Ari Franscisco de Araujo Júnior

(i) https://orcid.org/0000-0003-4353-8532

Possui graduação em Economia pela Universidade de São Paulo (1998) e mestrado em Teoria Econômica pela Universidade Federal de Minas Gerais (2001). Atualmente é professor assistente IV do Ibmec Minas Gerais. Tem experiência na área de Economia, com ênfase em Métodos e Modelos Matemáticos, Econométricos e Estatísticos, atuando principalmente nos seguintes temas: mortalidade, economia do crime, economia e esportes, desenvolvimento econômico e economia política positiva.

$@$ arifaj@gmail.com

\section{Tiago Silva Pires}

https://orcid.org/0000-0002-0672-6246

Graduado em Economia (2019) e Relações Internacionais (2017) pelo Ibmec Minas Gerais.

$®$ tiagosilva12@yahoo.com.br 